\section{Educação alimentar e nutricional em escolares: uma revisão de literatura}

\author{
Food and nutrition education in school: \\ a literature review
}

\section{Educación alimentaria y nutricional en las escuelas: una revisión de la literatura}

\begin{abstract}
Food and nutrition education is viewed as a key strategy for promoting healthy eating habits, and the school is an appropriate space for developing these activities. The objective of this study was to describe and analyze the scientific literature on intervention studies on food and nutrition education in Brazilian schools. A literature review was conducted, selecting articles published from 2000 to 2011. Despite the topic's current importance, there were few articles, and most were published after 2009. The main results showed improvement in the children's nutritional knowledge and food choices. However, most studies that performed anthropometric measurements failed to show changes in nutritional status. In addition, the studies chose designs based on epidemiological intervention studies, indicating the need for interventions based on innovative health education methodologies and research models that are consistent with the study's objects.
\end{abstract}

Food and Nutrition Education; School Health; School Feeding
Flavia Pascoal Ramos 1

Ligia Amparo da Silva Santos 1

Amélia Borba Costa Reis 1

\section{Resumo}

A educação alimentar e nutricional é vista como uma estratégia para promoção de hábitos alimentares saudáveis e acredita-se que a escola seja um espaço apropriado para desenvolver essas ações. Objetivou-se descrever e analisar o panorama da publicação científica sobre estudos de intervenção no campo da educação alimentar e nutricional em escolares no Brasil. Realizou-se uma revisão de literatura na qual foram selecionados artigos publicados entre 2000 e 2011. Observou-se que, apesar da relevância do tema, há um baixo número de publicações na área e que a maior parte foi publicada a partir de 2009. Os resultados apontados foram melhora no conhecimento em nutrição e nas opções alimentares. Entretanto, a maioria dos estudos que realizou avaliação antropométrica não encontrou mudanças no estado nutricional. Soma-se que os estudos optaram por metodologias baseadas nos estudos epidemiológicos de intervenção, indicando a necessidade de intervenções baseadas em metodologias inovadoras de educação em saúde, bem como modelos de pesquisa que correspondam aos objetos de estudo.

Educação Alimentar e Nutricional; Saúde Escolar; Alimentação Escolar 


\section{Introdução}

A Educação Alimentar e Nutricional (EAN) constitui uma estratégia preconizada pelas políticas públicas em alimentação e nutrição, sendo considerada um importante instrumento para promoção de hábitos alimentares saudáveis. $\mathrm{O}$ interesse pelo tema no Brasil surgiu na década de 1940 e, até 1970, esteve relacionada à introdução de alimentos novos para população por interesses econômicos, às publicações voltadas para divulgação de materiais informativos, e à adoção de medidas que privilegiavam a suplementação alimentar e atividades de combate a carências nutricionais específicas. Na década de 1970, por seu turno, houve referência à renda como principal obstáculo à alimentação adequada e nesse período a educação nutricional foi menos destacada nos programas de saúde pública por aproximadamente duas décadas 1 .

Ao realizar uma retrospectiva histórica do conhecimento produzido em cursos de pós-graduação em nutrição no período de 1980 a 1998, Lima et al. 2 destacam que o enfoque central da produção acadêmica em educação nutricional referente à década de 1980 até o ano de 1990 era de natureza intervencionista e técnica, mediado pela tese da ignorância alimentar e, a partir de 1990, foi notada a concepção crítica tanto na formação quanto na prática do nutricionista.

Percebeu-se a partir de então a relevância assumida pela EAN no âmbito das políticas públicas em alimentação e nutrição. A questão da promoção de hábitos alimentares saudáveis passou a constar nos programas oficiais brasileiros, a exemplo da Política Nacional de Alimentação e Nutrição (PNAN) 3, implantada no final da década de 1990, na qual se constata o fomento às ações em alimentação e nutrição, incluindo a perspectiva de acesso universal aos alimentos. Destaca-se ainda que no período de 1990 a 2010 os indivíduos passam a ser tratados como portadores de direitos e foram então convocados a ampliar seu poder de escolha e decisão 4 .

Abordagens semelhantes constam também na Estratégia Fome Zero 5, lançada em 2001, que contempla a importância da EAN associada à educação para o consumo e na Política Nacional de Promoção da Saúde 6, lançada em 2006, que prioriza as ações de promoção da alimentação saudável na qual a EAN aparece como estratégica no seu campo de atuação. O mesmo se observa na Política Nacional de Segurança Alimentar e Nutricional (PNSAN) 7 sancionada em 2010 com objetivo de assegurar o direito humano à alimentação adequada, tendo como base práticas alimentares promotoras de saúde.
Considerando a inexistência de diretrizes específicas que norteiam sua prática, em 2011 se desencadeou o 1o Encontro Nacional de Educação Alimentar e Nutricional - Discutindo Diretrizes, promovido pelo Ministério do Desenvolvimento Social em parceria com os Ministérios da Educação e da Saúde, visando ampliar a discussão sobre o tema no âmbito das políticas públicas e construir uma política intersetorial para formar bons hábitos alimentares ${ }^{8}$. Esse encontro juntamente com a Atividade Integradora sobre Educação Alimentar e Nutricional realizada durante a IVConferência Nacional de Segurança Alimentar e Nutricional, com a Oficina de Educação Alimentar e Nutricional nas Políticas Públicas realizada no congresso World Nutrition Rio 2012 em 2012, e com outros documentos resultou no Marco de Referência de Educação Alimentar e Nutricional para as Políticas Públicas ${ }^{9}$, lançado no final do referido ano com objetivo de promover um campo comum de reflexão e orientação da prática, no conjunto de iniciativas de EAN que tenham origem, especialmente, na ação pública, e que contemple os diversos setores vinculados ao processo de produção, distribuição, abastecimento e consumo de alimentos.

Quanto ao desafio de desenvolver ações em EAN apesar de sua relevância, o Marco de Referência 9 destaca que ainda é necessário ampliar a discussão sobre suas possibilidades, seus limites e o modo como são realizadas, uma vez que o seu campo de atuação não está claramente definido. Ressalta também a pouca visibilidade das experiências bem-sucedidas, assim como a fragilidade nos processos de planejamento.

No contexto escolar, a ausência de referências teórico-metodológicas que subsidiem as práticas de EAN também prevalece. Compreende-se que a formação dos hábitos alimentares é influenciada por fatores fisiológicos, psicológicos, socioculturais e econômicos e que têm sua formação iniciada na infância 10,11. Avalia-se, nesse contexto, hábito alimentar como um repertório de práticas alimentares que tendem a se repetir ao longo do tempo, e se frisa, nesse sentido, que é nessa fase da vida que o indivíduo sai do convívio basicamente familiar e penetra no contexto escolar, no qual experimentará outros alimentos e preparações e terá oportunidade de promover alterações nos seus hábitos alimentares pelas influências do grupo social e dos estímulos presentes no sistema educacional 11. Assim, entende-se que a escola apresenta um ambiente privilegiado para programas de EAN e essa conjuntura vem sendo considerada na formulação de políticas públicas em alimentação e nutrição.

O Programa Nacional de Alimentação Escolar (PNAE) 12, instituído no país desde 1955 e 
reformulado ao longo dos anos, apresenta entre seus objetivos a formação de hábitos alimentares saudáveis dos alunos, por meio de ações de EAN. Santos ${ }^{4}$ ressalta que no âmbito do Ministério da Educação, a escola tem sido um dos espaços mais focados pelas políticas públicas de alimentação e nutrição com a promoção da alimentação saudável, e cita a publicação, lançada em parceria com o Ministério da Saúde, da Portaria Interministerial no $1.010^{13}$, de 8 de maio de 2006, que institui as diretrizes para a promoção da alimentação saudável nas escolas de diferentes níveis. Vale destacar a instituição do Programa Saúde na Escola (PSE) através do Decreto no 6.286/2007 14 com objetivo de contribuir para a formação do estudante por meio de ações relacionadas à prevenção, atenção e promoção à saúde, incluindo nesse contexto a promoção da alimentação saudável.

Diante do exposto, ressalta-se a relevância dos estudos e pesquisas sobre o tema que possam colaborar para a construção de práticas educativas em alimentação e nutrição realmente eficazes. Todavia, as publicações de artigos científicos que indiquem como se conforma o campo da produção científica sobre a EAN em escolares são incipientes. Portanto, o objetivo deste trabalho foi descrever e analisar o panorama das publicações em periódicos científicos brasileiros sobre estudos de intervenção no campo da EAN em escolares no Brasil.

\section{Métodos}

Realizou-se uma revisão de literatura que utiliza as bases de dados LILACS e MEDLINE e a biblioteca eletrônica SciELO a fim de identificar artigos científicos publicados no período de 2000 a 2011. E de forma a localizar artigos não identificados em tal pesquisa, utilizou-se também a Biblioteca Virtual em Saúde (BVS), que integra as bases acima citadas.

A busca nas fontes supracitadas foi realizada tendo como termo indexador "educação nutricional" AND "escolares", e seu correspondente em inglês "nutrition education" AND "school" e "food and nutrition education". As publicações foram pré-selecionadas pelos títulos, os quais deveriam conter como primeiro critério o termo completo e/ou referências a escolares/ensino fundamental e consumo alimentar, hábitos alimentares ou alimentação saudável, acompanhada da leitura dos resumos disponíveis.

Foram incluídas publicações em inglês e português que atenderam aos critérios de se tratar de uma pesquisa, um estudo de intervenção; de apresentar como metodologia a descrição, apli- cação e/ou avaliação de uma intervenção em EAN em escolares desenvolvida no Brasil. Em seguida foram excluídos artigos repetidos em diferentes bases de dados. Realizou-se então uma pesquisa complementar no portal de periódicos da Capes e nas referências dos artigos selecionados com intuito de ampliar o campo empírico a ser analisado, e incluíram-se publicações que atendiam aos critérios supracitados. Ao final, foram selecionados 13 artigos resultantes das pesquisas nas bases e da pesquisa complementar para compor esta revisão.

A análise do material empírico selecionado tomou como referência a categorização dos estudos de acordo com o tipo do estudo e objetivos, local de realização da pesquisa, ano de publicação, as revistas nas quais foram veiculados, metodologias utilizadas e principais resultados encontrados.

\section{Resultados}

A busca bibliográfica, segundo a estratégia préestabelecida, resultou em dez artigos na base de dados LILACS, dois na base MEDLINE, oito na SciELO e oito na BVS, somando um total de 28 artigos. Após análise criteriosa, foram excluídos cinco por não se tratarem de estudo de intervenção diretamente com escolares e 13 por estarem repetidos nas diferentes bases. Por conseguinte, restaram cinco artigos na SciELO, quatro na base LILACS e um na BVS, totalizando dez artigos. A pesquisa complementar resultou em três artigos que atenderam ao critério de inclusão e foram acrescentados aos demais. Ao final, o material empírico desta revisão foi composto por 13 artigos.

Observou-se o baixo número de publicações na área de EAN em escolares, particularmente que seja um estudo de intervenção e descreva a metodologia utilizada como estratégia ao longo do trabalho. No presente estudo, $69,2 \%$ das pesquisas foram publicadas a partir do ano de 2009. A avaliação das revistas a que os estudos foram veiculados fundamentou-se na classificação de periódicos no Qualis/Capes, tendo como referência a área de avaliação de nutrição. Verificou-se que $53,8 \%$ se referem a revistas que não apresentam Fator de Impacto (FI), que indica a relevância das publicações científicas de acordo com o Journal Citations Reports (JCR). Não foram identificados estudos realizados nas regiões Norte e Nordeste, tendo $61,5 \%$ dos estudos avaliados concentrados na Região Sudeste com destaque ao Estado de São Paulo, 30,8\% realizados na Região Sul, especificamente em Santa Catarina e apenas $7,7 \%$ (um estudo) foi 
realizado na Região Centro-Oeste, conforme Tabela 1.

A Tabela 2 caracteriza os estudos quanto aos objetivos apresentados, metodologia empregada e os principais resultados alcançados. No que se refere aos objetivos, verificou-se que a maioria dos estudos objetivava avaliar uma intervenção em EAN sobre o grupo em estudo. Os termos utilizados para designar o objeto de avaliação foram diversos, com destaque para avaliar o "efeito", avaliar o "impacto", e avaliar a " aderência ao processo", como ainda "eficácia ou efetividade de uma ação ou programa" seja sobre mudanças no estado nutricional e/ou em conhecimentos em nutrição e nas práticas alimentares dos escolares. Chama a atenção o foco sobre combate e prevenção da obesidade. Apenas um artigo difere nesse sentido, pois expunha como objetivo apresentar métodos e tecnologias de intervenção em EAN.

As intervenções foram desenvolvidas de forma diversificada. A maioria apresentava mais de uma estratégia como palestras, apresentações, dinâmicas, histórias infantis e em quadrinhos, e muitas dessas utilizaram também atividades lúdicas com destaque para o teatro de fantoches e jogos educativos. Entretanto, algumas dessas estratégias não eram descritas no que se refere ao seu desenvolvimento metodológico. Quanto ao tempo de duração da intervenção, encontrou-se o período de um ano como o maior, enquanto o menor foi de 15 dias.

Os métodos de avaliação de intervenção utilizados nos estudos foram o conhecimento em nutrição e/ou o consumo alimentar por meio de questionários e a associação deles com a avaliação do estado nutricional pela antropometria; ambos foram empregados em proporções iguais. Outros métodos de avaliação foram usados por alguns estudos em menor expressão, como uso de atividades ilustrativas e jogos, relatados por apenas dois estudos, e entrevista semiestruturada relatada por um estudo. A maioria dos estudos aplicou os instrumentos antes e após a intervenção (logo após e até um ano depois), tendo alguns que utilizaram a comparação com um grupo controle. Destaca-se, dentre esses modos de análise, a avaliação do processo educacional apresentado por um estudo.

Os principais resultados encontrados em destaque pelos autores focaram nas mudanças do conhecimento em nutrição e nas opções alimentares que apresentaram, majoritariamente, mudanças positivas. Entre os estudos que realizaram avaliação antropométrica, apenas dois deles apontaram mudanças no estado nutricional, contudo um deles não realizou tratamento estatístico para verificar a significância entre os dois momentos. Um estudo apresentou como resultados o desenvolvimento de métodos e tecnologias de intervenção em EAN.

\section{Discussão}

O baixo número de publicações na área de EAN, particularmente em escolares, foi um aspecto demonstrado neste estudo. A título de exemplo, uma pesquisa de artigos utilizando o termo "educação alimentar e nutricional" na SciELO localizou 36 publicações diante de 432 com o termo "avaliação nutricional". Tal fato pode estar relacionado ao lugar que o tema da EAN tem historicamente ocupado no campo das políticas públicas e acadêmico-científico.

Sobre isso, destaca-se que a EAN não acompanhou da mesma maneira a consolidação enquanto um campo de conhecimentos como as demais áreas dentro do campo da nutrição, fato que representou certa limitação no seu desenvolvimento nos campos de prática e no aperfeiçoamento de suas bases teórico-metodológicas, bem como na produção acadêmico-científica. Santos 15 ressalta que embora a relevância da educação nutricional seja reconhecida atualmente, sobretudo nas políticas públicas em alimentação e nutrição, ainda há poucas referências quanto aos elementos que norteiam sua prática.

De forma interessante, a maioria dos estudos analisados foi publicada a partir de 2009. Tal ocorrência pode estar relacionada à maior ênfase dada ao tema nos últimos anos, contribuindo para o aumento progressivo do interesse sobre a temática. Santos 4 destaca que a partir de 2006 a EAN foi alvo de reflexão e debate, ocorrendo vários eventos específicos para tal fim. Soma-se o fato de que a alimentação escolar e na escola também tem tido visibilidade neste período por conta do estabelecimento de leis e normas que englobam a importância da promoção das práticas alimentares saudáveis nas escolas, a exemplo da Lei no 11.947/2009 12, da Portaria Interministerial no 1010/2006 13, da Resolução FNDE no 38/2009 16 e do Decreto no 6.286/2007 14. Ademais, ao realizar uma revisão sistemática sobre educação nutricional nas escolas, também buscando mapear recortes teórico-metodológicos com base em estudos publicados em periódicos nacionais e internacionais no período de 2000 a 2008, Pereira et al. 17 incluíram em seu trabalho apenas quatro estudos nacionais, o que pode sugerir que os estudos encontrados na presente revisão estivessem em fase de desenvolvimento.

Ainda que se tenha observado a crescente importância da EAN, um relevante percentual de suas publicações é veiculado em revistas que não possuem FI e que não estão bem conceituadas 
Categorização dos artigos que apresentam estudos de intervenção em educação alimentar e nutricional em escolares quanto ao tipo de estudo, local de realização e revista na qual foram veiculados, publicados no Brasil no período de 2000 a 2011.

\begin{tabular}{|c|c|c|c|c|}
\hline Estudo & Ano & Tipo do estudo & Local de realização da pesquisa & Revista \\
\hline Costa et al. 33 & 2009 & $\begin{array}{l}\text { Prospectivo longitudinal de } \\
\text { intervenção }\end{array}$ & Araçatuba (São Paulo); UNIP & $\begin{array}{c}\text { Revista do Instituto de Ciências } \\
\text { da Saúde }\end{array}$ \\
\hline Vargas et al. 21 & 2011 & Intervenção & Niterói (Rio de Janeiro); UFRJ & Revista de Saúde Pública \\
\hline Gabriel et al. 34 & 2008 & Intervenção & Florianópolis (Santa Catarina); UFSC & $\begin{array}{c}\text { Revista Brasileira de Saúde } \\
\text { Materno Infantil }\end{array}$ \\
\hline Fernandes et al. 27 & 2009 & Estudo de intervenção & Florianópolis (Santa Catarina); UFSC & Jornal de Pediatria \\
\hline Zancul \& Valeta 28 & 2009 & Intervenção & $\begin{array}{c}\text { Ribeirão Preto (São Paulo); } \\
\text { UnB/UNESP }\end{array}$ & $\begin{array}{l}\text { Nutrire: Revista da Sociedade } \\
\text { Brasileira de Alimentação e Nutrição }\end{array}$ \\
\hline Carvalho et al. 35 & 2010 & Estudo de intervenção & Belo Horizonte (Minas Gerais); UFMG & Pediatria (São Paulo) \\
\hline Deminice et al. 10 & 2007 & Estudo longitudinal & Ribeirão Preto (São Paulo); USP & Alimentos e Nutrição \\
\hline Anzolin et al. 36 & 2010 & Estudo de intervenção & Itajaí (Santa Catarina); UNIVALI & $\begin{array}{l}\text { Revista Brasileira em Promoção da } \\
\text { Saúde }\end{array}$ \\
\hline Gaglianone et al. 29 & 2006 & Ensaio clínico controlado & São Paulo; UNIFESP & Revista de Nutrição \\
\hline Garcia et al. 37 & 2008 & Estudo longitudinal & Itajaí (Santa Catarina); UNIVALI & RSBO \\
\hline Boog 38 & 2011 & Intervenção & $\begin{array}{l}\text { Cidade do interior de São Paulo; } \\
\text { UNICAMP }\end{array}$ & Revista de Nutrição \\
\hline Yokota et al. 39 & 2010 & Intervenção & Distrito Federal; UnB & Revista de Nutrição \\
\hline Botelho et al. 30 & 2010 & Estudo experimental de intervenção & Belo Horizonte (Minas Gerais); UFMG & $\begin{array}{l}\text { Nutrire: Revista da Sociedade } \\
\text { Brasileira de Alimentação e Nutrição }\end{array}$ \\
\hline
\end{tabular}

UFMG: Universidade Federal de Minas Gerais; UFRJ: Universidade Federal do Rio de Janeiro; UFSC: Universidade Federal de Santa Catarina; UnB: Universidade de Brasília; UNESP: Universidade Estadual Paulista; UNICAMP: Universidade Estadual de Campinas; UNIP: Universidade Paulista; UNIVALI: Universidade do Vale do Itajaí; USP: Universidade de São Paulo.

pelo Qualis/Capes. Essa constatação permite relacionar dois fatores que cerceiam as discussões sobre a mesma. O primeiro é quanto à marginalização do tema no campo científico conforme aludido anteriormente, e o segundo é quanto aos desenhos metodológicos utilizados nos estudos, que podem apresentar importantes fragilidades.

A maioria dos artigos analisados tomou como referência metodológica os estudos epidemiológicos de intervenção cujo objetivo é avaliar o efeito de um tratamento específico aplicado a uma amostra de sujeitos, testando-se seu efeito e como ele poderá ser mensurado e permitindo comparações que poderão ser feitas com outras intervenções ${ }^{18}$. Porém, ao se tratar de estudos no campo da educação tais metodologias apresentam limitações como o curto tempo entre a intervenção e a avaliação, o uso de questionários como a principal forma de avaliação e o não envolvimento da comunidade escolar - professores, funcionários e familiares dos escolares na intervenção.

Quanto aos principais métodos de avaliação das intervenções empregados pelos estudos analisados, verificou-se a predominância da avaliação do conhecimento, antropométrica e do consumo alimentar. Tal perspectiva se baseia na hipótese de que a apreensão de saber instituído leva à aquisição de novos comportamentos e práticas 19. Sobre isso, Bizzo \& Leder 20 (p. 663) sinalizam que "a eficácia da educação nutricional ao escolar não poderia estar circunscrita como simples verificação de conhecimentos, e sim evoluindo pela incorporação da avaliação de práticas e indicadores efetivos de saúde no decurso do processo educativo (avaliação de processo) $e$ convergindo para replanejamentos de aperfeiçoamento (produto de avaliação de resultado), sinergizada por complementaridade entre variáveis quantitativas e qualitativas". Em que pese a necessidade de aprofundamento sobre o que seja eficácia nas práticas de EAN, discute-se aqui a necessidade de uma avaliação crítica do processo educativo, e não somente dos resultados objetivos, considerando as suas complexidades.

Ao avaliar a intervenção por intermédio do consumo alimentar, observa-se uma limitação de grande relevância para os resultados encon- 
Tabela 2

Categorização dos artigos que apresentam estudos de intervenção em educação alimentar e nutricional em escolares quanto aos objetivos, metodologia e principais resultados, publicados no Brasil no período de 2000 a 2011.

\begin{tabular}{|c|c|c|c|c|c|c|c|}
\hline \multirow[t]{2}{*}{ Artigo } & \multirow[t]{2}{*}{ Ano } & \multirow[t]{2}{*}{ Objetivos } & \multicolumn{4}{|c|}{ Metodologia } & \multirow{2}{*}{$\begin{array}{l}\text { Principais } \\
\text { resultados }\end{array}$} \\
\hline & & & Público alvo & Período & Intervenção & $\begin{array}{l}\text { Avaliação da } \\
\text { intervenção }\end{array}$ & \\
\hline $\begin{array}{l}\text { Costa } \\
\text { et al. } 33\end{array}$ & 2009 & $\begin{array}{c}\text { Avaliar o } \\
\text { diagnóstico } \\
\text { nutricional, } \\
\text { o consumo } \\
\text { alimentar e } \\
\text { a aderência } \\
\text { ao processo } \\
\text { de educação } \\
\text { nutricional através } \\
\text { de conhecimentos } \\
\text { de nutrição em } \\
\text { crianças de } 7 \text { a } 10 \\
\text { anos }\end{array}$ & $\begin{array}{l}34 \text { crianças de } 7 \\
\text { a } 10 \text { anos de uma } \\
\text { escola particular }\end{array}$ & $\begin{array}{l}\text { Maio a junho de } \\
2007 \text { (7 semanas) }\end{array}$ & $\begin{array}{c}\text { Realizada através } \\
\text { de atividades } \\
\text { como palestras, } \\
\text { teatros de } \\
\text { fantoches, } \\
\text { dinâmicas de } \\
\text { grupo e arte } \\
\text { culinária }\end{array}$ & $\begin{array}{c}\text { Realizada nos } \\
\text { momentos } \\
\text { inicial e final (7 } \\
\text { semanas após } \\
\text { a intervenção) } \\
\text { através da } \\
\text { avaliação } \\
\text { antropométrica, } \\
\text { consumo } \\
\text { alimentar e } \\
\text { questionário de } \\
\text { conhecimento em } \\
\text { nutrição }\end{array}$ & $\begin{array}{c}\text { Não se observou } \\
\text { mudança } \\
\text { significativa quanto } \\
\text { a CC nem quanto } \\
\text { ao IMC. Observou- } \\
\text { se aumento do } \\
\text { conhecimento } \\
\text { em nutrição após } \\
\text { a intervenção e } \\
\text { da frequência } \\
\text { de consumo das } \\
\text { porções de cereais, } \\
\text { frutas, hortaliças, } \\
\text { carnes, ovos, } \\
\text { leguminosas, leite } \\
\text { e inclusive de } \\
\text { alimentos do topo } \\
\text { da pirâmide }\end{array}$ \\
\hline $\begin{array}{l}\text { Vargas } \\
\text { et al. } 21\end{array}$ & 2011 & $\begin{array}{l}\text { Avaliar os efeitos } \\
\text { de um programa } \\
\text { de prevenção } \\
\text { de obesidade } \\
\text { sobre as práticas } \\
\text { alimentares de } \\
\text { adolescentes de } \\
\text { escolas públicas }\end{array}$ & $\begin{array}{l}331 \text { estudantes } \\
\text { de } 5 \text { o e } 60 \\
\text { anos do Ensino } \\
\text { Fundamental de } \\
2 \text { escolas da rede } \\
\text { pública estadual }\end{array}$ & $\begin{array}{c}\text { Agosto a } \\
\text { novembro de } \\
2005 \text { (3 meses) }\end{array}$ & $\begin{array}{l}\text { O programa foi } \\
\text { desenvolvido em } \\
2 \text { escolas, uma } \\
\text { intervenção e } \\
\text { outra, controle. As } \\
\text { atividades foram } \\
\text { desenvolvidas } \\
\text { utilizando } \\
\text { como recursos: } \\
\text { dinâmicas, filmes, } \\
\text { discussões, } \\
\text { apresentações } \\
\text { e oficinas. As } \\
\text { temáticas de } \\
\text { interesse foram } \\
\text { definidas a } \\
\text { partir de grupos } \\
\text { focais na fase } \\
\text { pré-intervenção } \\
\text { com opiniões e } \\
\text { sugestões dos } \\
\text { docentes }\end{array}$ & $\begin{array}{l}\text { Realizou-se } \\
\text { avaliação } \\
\text { antropométrica } \\
\text { no período pré- } \\
\text { intervenção. E } \\
\text { aplicação de } \\
\text { questionário auto } \\
\text { respondido, nas } \\
\text { fases pré e pós- } \\
\text { intervenção }\end{array}$ & $\begin{array}{c}\text { Aumentaram } \\
\text { na Escola a } \\
\text { intervenção e a } \\
\text { proporção de } \\
\text { jovens que relatou } \\
\text { "nunca ou quase } \\
\text { nunca" consumir } \\
\text { lanches vendidos } \\
\text { por ambulantes e } \\
\text { decresceu também } \\
\text { a substituição } \\
\text { do almoço ou } \\
\text { jantar por lanche. } \\
\text { Observou-se } \\
\text { uma redução } \\
\text { significativa do } \\
\text { consumo da } \\
\text { merenda oferecida } \\
\text { pela escola. Na } \\
\text { Escola Controle, } \\
\text { observou-se } \\
\text { redução no } \\
\text { consumo de frutas } \\
\text { e legumes pelos } \\
\text { jovens }\end{array}$ \\
\hline
\end{tabular}

(continua) 
Tabela 2 (continuação)

\begin{tabular}{|c|c|c|c|c|c|c|c|}
\hline \multirow[t]{2}{*}{ Artigo } & \multirow[t]{2}{*}{ Ano } & \multirow[t]{2}{*}{ Objetivos } & \multicolumn{4}{|c|}{ Metodologia } & \multirow{2}{*}{$\begin{array}{l}\text { Principais } \\
\text { resultados }\end{array}$} \\
\hline & & & Público alvo & Período & Intervenção & $\begin{array}{l}\text { Avaliação da } \\
\text { intervenção }\end{array}$ & \\
\hline $\begin{array}{l}\text { Gabriel } \\
\text { et al. } 34\end{array}$ & 2008 & $\begin{array}{c}\text { Avaliar os } \\
\text { resultados de } \\
\text { um programa } \\
\text { de intervenção } \\
\text { nutricional visando } \\
\text { à promoção } \\
\text { de hábitos } \\
\text { alimentares } \\
\text { saudáveis } \\
\text { em escolares } \\
\text { do Ensino } \\
\text { Fundamental }\end{array}$ & $\begin{array}{c}162 \text { escolares } \\
\text { das 3a e 4a séries } \\
\text { de uma escola } \\
\text { pública e das } 3 \text { ass } \\
\text { séries de uma } \\
\text { escola particular }\end{array}$ & $\begin{array}{l}\text { Março a julho de } \\
2004 \text { (4 meses) }\end{array}$ & $\begin{array}{c}\text { Atividades } \\
\text { desenvolvidas em } \\
\text { sete encontros. } \\
\text { O planejamento } \\
\text { das atividades } \\
\text { foi aprimorado } \\
\text { por profissionais } \\
\text { como nutricionista } \\
\text { e pedagoga. } \\
\text { O artigo não } \\
\text { descreve } \\
\text { detalhadamente } \\
\text { a metodologia } \\
\text { utilizada, apenas } \\
\text { cita os assuntos } \\
\text { abordados em } \\
\text { cada encontro } \\
\text { incluindo o } \\
\text { desenvolvimento } \\
\text { de um jogo } \\
\text { para avaliar os } \\
\text { conhecimentos } \\
\text { adquiridos }\end{array}$ & $\begin{array}{l}\text { Foi realizada } \\
\text { avaliação } \\
\text { do consumo } \\
\text { alimentar sobre } \\
\text { o período de } \\
\text { permanência na } \\
\text { escola, com bloco } \\
\text { específico para } \\
\text { merenda ofertada } \\
\text { na escola pública } \\
\text { e avaliação } \\
\text { antropométrica, } \\
\text { ambas no } \\
\text { período pré e } \\
\text { um mês após a } \\
\text { intervenção }\end{array}$ & $\begin{array}{c}\text { Não houve } \\
\text { mudanças } \\
\text { significativas } \\
\text { nas prevalências } \\
\text { de sobrepeso/ } \\
\text { obesidade e dos } \\
\text { alimentos mais } \\
\text { adquiridos nas } \\
\text { instituições. Após } \\
\text { a intervenção na } \\
\text { escola pública, } \\
\text { apenas os } \\
\text { meninos sugeriram } \\
\text { alimentos mais } \\
\text { saudáveis e para } \\
\text { ambos aumentou } \\
\text { a aceitação das } \\
\text { frutas. Na escola } \\
\text { privada, não houve } \\
\text { mais referências a } \\
\text { guloseimas }\end{array}$ \\
\hline $\begin{array}{l}\text { Fernandes } \\
\text { et al. } 27\end{array}$ & 2009 & $\begin{array}{l}\text { Apresentar os } \\
\text { resultados de } \\
\text { um estudo de } \\
\text { intervenção } \\
\text { controlado sobre } \\
\text { a efetividade de } \\
\text { um programa } \\
\text { de educação } \\
\text { nutricional visando } \\
\text { à prevenção } \\
\text { da obesidade } \\
\text { e melhorias no } \\
\text { perfil de consumo } \\
\text { alimentar dos } \\
\text { escolares da 2a } \\
\text { série do Ensino } \\
\text { Fundamental } \\
\text { de } 2 \text { escolas do } \\
\text { Município de } \\
\text { Florianópolis/SC }\end{array}$ & $\begin{array}{c}134 \text { escolares da } \\
\text { 2aa série do Ensino } \\
\text { Fundamental de } 2 \\
\text { instituições (uma } \\
\text { pública e outra } \\
\text { privada) }\end{array}$ & $\begin{array}{l}\text { Março a julho de } \\
2006 \text { (4 meses); } \\
8 \text { encontros } \\
\text { quinzenais }\end{array}$ & $\begin{array}{c}\text { Os escolares } \\
\text { divididos em dois } \\
\text { grupos com e } \\
\text { sem intervenção. } \\
\text { O conteúdo do } \\
\text { programa foi } \\
\text { ministrado a } \\
\text { partir de métodos } \\
\text { lúdico-educativos, } \\
\text { utilizando } \\
\text { jogos, teatros } \\
\text { de fantoches, } \\
\text { cartazes, } \\
\text { brincadeiras, } \\
\text { músicas e histórias } \\
\text { infantis }\end{array}$ & $\begin{array}{l}\text { Foi realizada } \\
\text { avaliação } \\
\text { antropométrica } \\
\text { e avaliação } \\
\text { do consumo } \\
\text { alimentar sobre } \\
\text { o período de } \\
\text { permanência } \\
\text { na escola, } \\
\text { preenchido pelo } \\
\text { próprio aluno. } \\
\text { Dados coletados } \\
\text { antes e após a } \\
\text { intervenção }\end{array}$ & $\begin{array}{l}\text { Não se observou } \\
\text { diferenças } \\
\text { significativas } \\
\text { na prevalência } \\
\text { de excesso de } \\
\text { peso. As turmas } \\
\text { com intervenção } \\
\text { diminuíram } \\
\text { consumo de } \\
\text { suco artificial e } \\
\text { as turmas sem } \\
\text { intervenção } \\
\text { aumentaram } \\
\text { o consumo de } \\
\text { salgadinho. } \\
\text { Houve aumento } \\
\text { no consumo de } \\
\text { refrigerantes em } \\
\text { ambas as turmas, } \\
\text { com significância } \\
\text { na sem intervenção }\end{array}$ \\
\hline
\end{tabular}

(continua) 
Tabela 2 (continuação)

\begin{tabular}{|c|c|c|c|c|c|c|c|}
\hline \multirow[t]{2}{*}{ Artigo } & \multirow[t]{2}{*}{ Ano } & \multirow[t]{2}{*}{ Objetivos } & \multicolumn{4}{|c|}{ Metodologia } & \multirow{2}{*}{$\begin{array}{l}\text { Principais } \\
\text { resultados }\end{array}$} \\
\hline & & & Público alvo & Período & Intervenção & $\begin{array}{l}\text { Avaliação da } \\
\text { intervenção }\end{array}$ & \\
\hline $\begin{array}{l}\text { Zancul \& } \\
\text { Valeta } 28\end{array}$ & 2009 & $\begin{array}{c}\text { Analisar os reflexos } \\
\text { de um programa de } \\
\text { educação nutricional } \\
\text { nas condutas } \\
\text { alimentares de } \\
\text { alunos da 6a série } \\
\text { de uma escola } \\
\text { da rede pública } \\
\text { municipal, e verificar } \\
\text { se a intervenção } \\
\text { foi capaz de } \\
\text { provocar mudanças } \\
\text { comportamentais nos } \\
\text { hábitos alimentares } \\
\text { e no estilo de vida } \\
\text { desses adolescentes }\end{array}$ & $\begin{array}{l}36 \text { alunos de uma } \\
\text { escola municipal, } \\
\text { de ambos os } \\
\text { gêneros, com } \\
\text { idades entre } 11 \text { e } \\
14 \text { anos }\end{array}$ & Um semestre & $\begin{array}{c}\text { Consistiu em } \\
\text { discussões, } \\
\text { apresentação de } \\
\text { filmes, elaboração } \\
\text { de cartazes, } \\
\text { dramatização, leitura } \\
\text { de textos, aplicação } \\
\text { de jogos e dinâmicas. } \\
\text { A cada tema foram } \\
\text { debatidas as } \\
\text { concepções prévias } \\
\text { dos estudantes, } \\
\text { considerando-se } \\
\text { as necessidades } \\
\text { de informação } \\
\text { demonstradas, } \\
\text { buscando ampliar o } \\
\text { enfoque para além do } \\
\text { biologicista }\end{array}$ & $\begin{array}{c}\text { Foi realizada } \\
\text { através de } \\
\text { questionário } \\
\text { sobre alimentação } \\
\text { dentro e fora da } \\
\text { escola, antes do } \\
\text { programa, logo } \\
\text { após e } 8 \text { meses } \\
\text { depois }\end{array}$ & $\begin{array}{l}\text { Observou-se aumento } \\
\text { no consumo do } \\
\text { desjejum logo após } \\
\text { a intervenção, com } \\
\text { decréscimo na } \\
\text { segunda avaliação } \\
\text { e do consumo de } \\
\text { alimentos oferecidos } \\
\text { na merenda } \\
\text { escolar logo após a } \\
\text { intervenção. Foram } \\
\text { considerados pelos } \\
\text { alunos como alimentos } \\
\text { saudáveis o arroz, } \\
\text { feijão, salada e frutas. } \\
\text { E como não saudáveis } \\
\text { refrigerantes, salgados } \\
\text { e doces }\end{array}$ \\
\hline $\begin{array}{l}\text { Carvalho } \\
\text { et al. } 35\end{array}$ & 2011 & $\begin{array}{c}\text { Avaliar } \\
\text { qualitativamente o } \\
\text { consumo alimentar } \\
\text { e o impacto da } \\
\text { promoção de hábitos } \\
\text { alimentares saudáveis } \\
\text { em escolares do } \\
\text { primeiro ciclo de } \\
\text { ensino de uma escola } \\
\text { municipal de Belo } \\
\text { Horizonte/MG }\end{array}$ & $\begin{array}{c}135 \text { escolares } \\
\text { do primeiro ciclo } \\
\text { de uma escola } \\
\text { municipal }\end{array}$ & $\begin{array}{c}3 \text { meses } \\
\text { (4 encontros) }\end{array}$ & $\begin{array}{c}\text { Foi realizada por } \\
\text { meio de diálogo e } \\
\text { material ilustrativo, } \\
\text { exposição e } \\
\text { degustação de sucos. } \\
\text { Os temas abordados } \\
\text { foram discutidos } \\
\text { previamente com a } \\
\text { direção e o corpo } \\
\text { docente da escola }\end{array}$ & $\begin{array}{l}\text { Foi realizada } \\
\text { por meio de } \\
\text { questionário } \\
\text { autoexplicativo } \\
\text { aplicado no início } \\
\text { e ao final das } \\
\text { atividades }\end{array}$ & $\begin{array}{c}\text { Após a intervenção } \\
\text { observou-se aumento } \\
\text { no número de } \\
\text { questões relativas } \\
\text { ao micronutriente } \\
\text { cálcio, as questões } \\
\text { sobre o micronutriente } \\
\text { ferro e a pirâmide } \\
\text { alimentar não foram } \\
\text { estatisticamente } \\
\text { significante }\end{array}$ \\
\hline $\begin{array}{l}\text { Deminice } \\
\text { et al. } 10\end{array}$ & 2007 & $\begin{array}{l}\text { Desenvolver e } \\
\text { implementar } \\
\text { um programa } \\
\text { de educação } \\
\text { alimentar e avaliar } \\
\text { seus efeitos sobre } \\
\text { o NCAN, sobre PA } \\
\text { e sobre o estado } \\
\text { nutricional, além } \\
\text { de determinar o } \\
\text { NAF de alunos } \\
\text { de uma escola } \\
\text { de ensino } \\
\text { fundamental da } \\
\text { rede municipal de } \\
\text { Ribeirão Preto/SP }\end{array}$ & $\begin{array}{l}951 \text { alunos de } \\
\text { uma escola } \\
\text { municipal } \\
\text { de ensino } \\
\text { fundamental }\end{array}$ & 6 meses & $\begin{array}{c}\text { Foram } \\
\text { desenvolvidas } \\
\text { estratégias e } \\
\text { materiais como } \\
\text { painéis coloridos, } \\
\text { transparências, } \\
\text { fantoches, } \\
\text { brincadeiras, } \\
\text { vídeos e figuras } \\
\text { de alimentos. } \\
\text { Foram realizadas } \\
\text { também avaliação } \\
\text { antropométrica e } \\
\text { determinação do } \\
\text { NAF }\end{array}$ & $\begin{array}{l}\text { Foi realizada } \\
\text { através de dois } \\
\text { questionários } \\
\text { sendo um } \\
\text { sobre NCAN e } \\
\text { outro sobre PA } \\
\text { aplicados em } \\
\text { uma amostra } \\
\text { de alunos, bem } \\
\text { como através } \\
\text { da avaliação } \\
\text { antropométrica } \\
\text { em todos } \\
\text { indivíduos no } \\
\text { período pré e pós } \\
\text { intervenção }\end{array}$ & $\begin{array}{c}\text { Observou-se aumento } \\
\text { estatisticamente } \\
\text { significante com } \\
\text { relação ao NCAN e } \\
\text { PA, entretanto, não } \\
\text { foram encontradas } \\
\text { correlações } \\
\text { entre o NCNA e } \\
\text { PA. Observou- } \\
\text { se diminuição } \\
\text { de subnutridos } \\
\text { e aumento de } \\
\text { indivíduos eutróficos } \\
\text { e com sobrepeso } \\
\text { no sexo masculino } \\
\text { enquanto no feminino } \\
\text { houve diminuição } \\
\text { de subnutridos e } \\
\text { eutróficos e aumento } \\
\text { de sobrepeso e } \\
\text { obesidade }\end{array}$ \\
\hline
\end{tabular}

(continua) 
Tabela 2 (continuação)

\begin{tabular}{|c|c|c|c|c|c|c|c|}
\hline \multirow[t]{2}{*}{ Artigo } & \multirow[t]{2}{*}{ Ano } & \multirow[t]{2}{*}{ Objetivos } & \multicolumn{4}{|c|}{ Metodologia } & \multirow{2}{*}{$\begin{array}{l}\text { Principais } \\
\text { resultados }\end{array}$} \\
\hline & & & Público alvo & Período & Intervenção & $\begin{array}{l}\text { Avaliação da } \\
\text { intervenção }\end{array}$ & \\
\hline $\begin{array}{l}\text { Anzolin } \\
\text { et al. } 36\end{array}$ & 2010 & $\begin{array}{c}\text { Verificar a } \\
\text { efetividade de } \\
\text { intervenções } \\
\text { nutricionais entre } \\
\text { escolares de 1ạ a } \\
\text { 4ạ série de escola } \\
\text { de ensino privado } \\
\text { no Município de } \\
\text { Itajaí/SC }\end{array}$ & $\begin{array}{l}\text { Crianças de } 6 \\
\text { a } 10 \text { anos, de } \\
\text { ambos os sexos, } \\
\text { matriculadas de 1ạ } \\
\text { a } 4 \text { a série de uma } \\
\text { escola privada }\end{array}$ & $\begin{array}{c}\text { Agosto a } \\
\text { novembro de } \\
2008\end{array}$ & $\begin{array}{l}\text { Desenvolvida em } \\
4 \text { encontros sendo } \\
\text { os } 2 \text { primeiros } \\
\text { por meio de } \\
\text { palestras, o } \\
\text { terceiro envolveu } \\
\text { a realização } \\
\text { de um lanche } \\
\text { e no quarto } \\
\text { foram realizadas } \\
\text { atividades lúdicas }\end{array}$ & $\begin{array}{c}\text { Através da } \\
\text { comparação } \\
\text { da frequência } \\
\text { alimentar de } \\
\text { antes e após } \\
\text { a intervenção. } \\
\text { Realizou-se } \\
\text { avaliação } \\
\text { antropométrica } \\
\text { apenas no } \\
\text { período pré- } \\
\text { intervenção }\end{array}$ & $\begin{array}{c}\text { Observou-se } \\
\text { que a frequência } \\
\text { do consumo de } \\
\text { doces reduziu } \\
\text { pela metade após } \\
\text { a intervenção, } \\
\text { e o de pizza e } \\
\text { hambúrguer } \\
\text { aumentou. } \\
\text { Observou-se que } \\
\text { todos os grupos } \\
\text { alimentares (frutas, } \\
\text { feijão e arroz, } \\
\text { refrigerantes } \\
\text { e legumes) } \\
\text { tiveram aumento } \\
\text { significativo na } \\
\text { preferência referida } \\
\text { pelas crianças após } \\
\text { a intervenção }\end{array}$ \\
\hline $\begin{array}{l}\text { Gaglianone } \\
\text { et al. } 29\end{array}$ & 2006 & $\begin{array}{c}\text { Analisar o } \\
\text { desenvolvimento, } \\
\text { implementação } \\
\text { e impacto de } \\
\text { um programa } \\
\text { de educação } \\
\text { nutricional sobre } \\
\text { conhecimentos } \\
\text { e atitudes } \\
\text { relativos a hábitos } \\
\text { alimentares } \\
\text { saudáveis } \\
\text { de alunos e } \\
\text { professores }\end{array}$ & $\begin{array}{l}803 \text { estudantes } \\
\text { de } 7 \text { a } 10 \text { anos, } \\
\text { de ambos os } \\
\text { sexos, da 1ạ e } \\
\text { 2a série de } 8 \\
\text { escolas de Ensino } \\
\text { Fundamental } \\
\text { (367 do grupo de } \\
\text { intervenção e } 436 \\
\text { grupo controle) }\end{array}$ & 5 meses & $\begin{array}{l}\text { Dividido em } \\
2 \text { grupos } \\
\text { intervenção } \\
\text { e controle. A } \\
\text { atividade foi } \\
\text { desenvolvida } \\
\text { através de jogos } \\
\text { educacionais } \\
\text { e histórias. } \\
\text { Professores } \\
\text { inicialmente } \\
\text { foram treinados } \\
\text { pela equipe do } \\
\text { projeto para após } \\
\text { esse processo } \\
\text { implantarem o } \\
\text { programa em suas } \\
\text { aulas }\end{array}$ & $\begin{array}{c}\text { Realizada através } \\
\text { de ilustrações } \\
\text { antes de iniciar } \\
\text { a intervenção e } \\
\text { um ano depois. } \\
\text { Os professores } \\
\text { também } \\
\text { responderam a um } \\
\text { questionário de } \\
\text { perguntas abertas }\end{array}$ & $\begin{array}{c}\text { Observou-se } \\
\text { aumento na } \\
\text { preferência por } \\
\text { grãos e grupos de } \\
\text { cereais no grupo } \\
\text { de intervenção } \\
\text { e decréscimo na } \\
\text { preferência por } \\
\text { alimentos ricos em } \\
\text { gorduras e açúcar. } \\
\text { Houve aumento } \\
\text { do conhecimento } \\
\text { sobre nutrição } \\
\text { entre os } \\
\text { professores } \\
\text { do grupo de } \\
\text { intervenção }\end{array}$ \\
\hline $\begin{array}{l}\text { Garcia } \\
\text { et al. } 37\end{array}$ & 2008 & $\begin{array}{c}\text { Avaliar o estado } \\
\text { nutricional e } \\
\text { de higiene oral } \\
\text { de escolares } \\
\text { pertencentes ao } \\
\text { Programa AABB } \\
\text { Comunidade e } \\
\text { verificar a eficácia } \\
\text { da aplicação da } \\
\text { educação em saúde } \\
\text { na modulação dos } \\
\text { estados nutricional e } \\
\text { de saúde oral }\end{array}$ & $\begin{array}{c}\text { Escolares de } 8 \\
\text { a } 15 \text { anos do } \\
\text { Programa AABB } \\
\text { Comunidade }\end{array}$ & $\begin{array}{c}\text { Agosto a } \\
\text { novembro de } \\
2007 \text { (4 meses) }\end{array}$ & $\begin{array}{l}\text { Realizou-se } \\
\text { por meio de } \\
\text { diferentes } \\
\text { metodologias, } \\
\text { que incluíram } \\
\text { dinâmicas de } \\
\text { grupo, palestras, } \\
\text { jogos educativos, } \\
\text { pintura, desenho } \\
\text { e realização de } \\
\text { exercícios com } \\
\text { temas de Nutrição } \\
\text { e de Odontologia }\end{array}$ & $\begin{array}{c}\text { Realizada } \\
\text { através de dados } \\
\text { antropométricos } \\
\text { antes e após a } \\
\text { intervenção }\end{array}$ & $\begin{array}{l}\text { Melhora no } \\
\text { estado nutricional } \\
\text { (aumento no } \\
\text { número de } \\
\text { eutróficos, } \\
\text { diminuição } \\
\text { no número de } \\
\text { sobrepeso e de } \\
\text { risco nutricional) }\end{array}$ \\
\hline
\end{tabular}

(continua) 
Tabela 2 (continuação)

\begin{tabular}{|c|c|c|c|c|c|c|c|}
\hline \multirow[t]{2}{*}{ Artigo } & \multirow[t]{2}{*}{ Ano } & \multirow[t]{2}{*}{ Objetivos } & \multicolumn{4}{|c|}{ Metodologia } & \multirow{2}{*}{$\begin{array}{l}\text { Principais } \\
\text { resultados }\end{array}$} \\
\hline & & & Público alvo & Período & Intervenção & $\begin{array}{l}\text { Avaliação da } \\
\text { intervenção }\end{array}$ & \\
\hline Boog 38 & 2010 & $\begin{array}{l}\text { Apresentar } \\
\text { métodos e } \\
\text { tecnologias de } \\
\text { intervenção } \\
\text { em educação } \\
\text { alimentar e } \\
\text { nutricional criados } \\
\text { com base em } \\
\text { diagnóstico } \\
\text { realizado no } \\
\text { âmbito de escola } \\
\text { e comunidade, } \\
\text { tendo como } \\
\text { pressuposto } \\
\text { teórico a } \\
\text { relação homem/ } \\
\text { ambiente, } \\
\text { mediada pelo } \\
\text { trabalho }\end{array}$ & $\begin{array}{c}155 \text { alunos da pré } \\
\text { escola a } 7 \text { série } \\
\text { de uma escola da } \\
\text { zona rural }\end{array}$ & $\begin{array}{c}15 \text { dias (cinco } \\
\text { etapas) }\end{array}$ & $\begin{array}{l}\text { O método } \\
\text { empregado e } \\
\text { as tecnologias } \\
\text { desenvolvidas foram } \\
\text { pautadas sobre } \\
\text { os conceitos de } \\
\text { promoção da saúde, } \\
\text { nutrição comunitária e } \\
\text { educação nutricional } \\
\text { problematizadora. } \\
\text { A intervenção } \\
\text { foi denominada } \\
\text { "Ensinando a amar a } \\
\text { terra e o que a terra } \\
\text { produz". Na sua } \\
\text { concepção, procurou- } \\
\text { se contextualizar } \\
\text { o tema tratado no } \\
\text { cotidiano de vida } \\
\text { da comunidade e } \\
\text { na ampliação da } \\
\text { compreensão dos } \\
\text { professores sobre a } \\
\text { realidade de vida das } \\
\text { famílias dos alunos }\end{array}$ & $\begin{array}{c}\text { Houve grande } \\
\text { interesse dos } \\
\text { alunos porque a } \\
\text { maquete refletia } \\
\text { o seu cotidiano } \\
\text { e valorizava o } \\
\text { trabalho e a } \\
\text { história de suas } \\
\text { famílias }\end{array}$ & $\begin{array}{l}\text { A implementação do } \\
\text { programa ocorreu no } \\
\text { final do ano letivo, } \\
\text { cerca de } 15 \text { dias } \\
\text { antes do término das } \\
\text { aulas, em } 5 \text { etapas. } \\
\text { Foram realizadas } \\
\text { atividades como } \\
\text { conto de história que } \\
\text { valorizou o contexto } \\
\text { local, palavras } \\
\text { cruzadas, calendário } \\
\text { agrícola, caça- } \\
\text { palavras, construção } \\
\text { de maquete e } \\
\text { degustação da fruta } \\
\text { produzida na região. } \\
\text { E todas as atividades } \\
\text { foram desenvolvidas } \\
\text { a partir de elementos } \\
\text { baseadas na realidade } \\
\text { local }\end{array}$ \\
\hline $\begin{array}{l}\text { Yokota } \\
\text { et al. } 39\end{array}$ & 2010 & $\begin{array}{c}\text { Analisar e } \\
\text { comparar o } \\
\text { conhecimento } \\
\text { sobre nutrição } \\
\text { de professores } \\
\text { e alunos } \\
\text { participantes do } \\
\text { Projeto "A escola } \\
\text { promovendo } \\
\text { hábitos } \\
\text { alimentares } \\
\text { saudáveis", } \\
\text { submetidos a } \\
2 \text { estratégias } \\
\text { de educação } \\
\text { nutricional }\end{array}$ & $\begin{array}{c}180 \text { alunos de } \\
5 \text { a } 10 \text { anos e } \\
19 \text { professores } \\
\text { (4 escolas com } \\
\text { intervenção A) e } \\
129 \text { alunos e } 16 \\
\text { professores (4 } \\
\text { com intervenção } \\
\text { B) }\end{array}$ & $\begin{array}{l}\text { Refere período } \\
\text { de avaliação } \\
\text { janeiro de } 2004 \\
\text { a dezembro de } \\
2005\end{array}$ & $\begin{array}{l}\text { Foram utilizadas } \\
2 \text { estratégias } \\
\text { de intervenção. } \\
\text { Intervenção A na qual } \\
\text { as ações educativas } \\
\text { foram desenvolvidas } \\
\text { pela equipe do } \\
\text { projeto, por meio de } \\
\text { palestras educativas } \\
\text { com todas as turmas } \\
\text { de educação infantil } \\
\text { e fundamental; e } \\
\text { Intervenção B na qual } \\
\text { as ações educativas } \\
\text { foram desenvolvidas } \\
\text { por professores } \\
\text { que frequentaram } \\
\text { oficinas temáticas de } \\
\text { capacitação. Artigo } \\
\text { não descreve como } \\
\text { foram aplicadas as } \\
\text { intervenções e o } \\
\text { conteúdo abordado }\end{array}$ & $\begin{array}{l}\text { O conhecimento } \\
\text { das crianças foi } \\
\text { avaliado através } \\
\text { de instrumentos } \\
\text { quantitativos } \\
\text { com formato de } \\
\text { figuras e jogos. } \\
\text { E a avaliação dos } \\
\text { professores foi } \\
\text { realizada por meio } \\
\text { de questionário }\end{array}$ & $\begin{array}{c}\text { A média de } \\
\text { acertos foi similar } \\
\text { nos } 2 \text { tipos de } \\
\text { intervenção para } \\
\text { os dois métodos } \\
\text { de avaliação } \\
\text { empregados. } \\
\text { Quanto aos } \\
\text { professores a } \\
\text { média de acertos } \\
\text { também foi similar }\end{array}$ \\
\hline
\end{tabular}

(continua) 
Tabela 2 (continuação)

\begin{tabular}{|c|c|c|c|c|c|c|c|}
\hline \multirow[t]{2}{*}{ Artigo } & \multirow[t]{2}{*}{ Ano } & \multirow[t]{2}{*}{ Objetivos } & \multicolumn{4}{|c|}{ Metodologia } & \multirow{2}{*}{$\begin{array}{l}\text { Principais } \\
\text { resultados }\end{array}$} \\
\hline & & & Público alvo & Período & Intervenção & $\begin{array}{l}\text { Avaliação da } \\
\text { intervenção }\end{array}$ & \\
\hline $\begin{array}{l}\text { Botelho } \\
\text { et al. } 30\end{array}$ & 2010 & $\begin{array}{c}\text { Avaliar o } \\
\text { aprendizado e as } \\
\text { percepções dos } \\
\text { escolares de uma } \\
\text { Escola Municipal } \\
\text { do Distrito } \\
\text { Sanitário Leste de } \\
\text { Belo Horizonte/ } \\
\text { MG, participantes } \\
\text { de um grupo } \\
\text { operativo sobre } \\
\text { a promoção da } \\
\text { alimentação } \\
\text { saudável }\end{array}$ & $\begin{array}{l}48 \text { escolares de } 6 \\
\text { a } 10 \text { anos de uma } \\
\text { escola municipal }\end{array}$ & $\begin{array}{c}\text { Cerca de } 3 \\
\text { meses }\end{array}$ & $\begin{array}{l}\text { Utilizou-se como } \\
\text { referencial a } \\
\text { estratégia de } \\
\text { grupo operativo, } \\
\text { uma técnica de } \\
\text { trabalho coletivo, } \\
\text { cujo objetivo } \\
\text { foi promover a } \\
\text { aprendizagem. } \\
\text { As oficinas foram } \\
\text { desenvolvidas } \\
\text { através de } \\
\text { explanação } \\
\text { dialogada sobre } \\
\text { o assunto com } \\
\text { auxílio de teatro } \\
\text { de fantoches; } \\
\text { Atividades lúdicas } \\
\text { (jogo da memória, } \\
\text { "batata-quente” } \\
\text { etc.); Parceria } \\
\text { com equipe de } \\
\text { odontologia } \\
\text { para oficina de } \\
\text { açúcares e doces }\end{array}$ & $\begin{array}{l}\text { Foi realizada por } \\
\text { meio de entrevista } \\
\text { semi estruturada } \\
3 \text { meses após as } \\
\text { oficinas }\end{array}$ & $\begin{array}{c}\text { A avaliação } \\
\text { demonstrou } \\
\text { que as oficinas } \\
\text { apresentaram um } \\
\text { impacto positivo } \\
\text { nas crianças } \\
\text { (as mesmas } \\
\text { recordavam os } \\
\text { pontos- chave } \\
\text { das atividades, } \\
\text { recomendações } \\
\text { etc.) e que } \\
\text { as respostas } \\
\text { às atividades } \\
\text { corresponderam, } \\
\text { em sua maioria, ao } \\
\text { esperado }\end{array}$ \\
\hline
\end{tabular}

CC: circunferência da cintura; IMC: índice de massa corporal; MG: Estado de Minas Gerais; NAF: nível de atividade física; NCAN: nível de conhecimento em alimentação e nutrição; PA: práticas alimentares; SC: Estado de Santa Catarina; SP: Estado de São Paulo.

trados, pois o conhecimento previamente adquirido pode se confundir com a prática efetiva. Vargas et al. 21 (p. 65) ressaltam em seu estudo que "é possível que os estudantes não tenham modificado suas práticas, mas reportado práticas mais adequadas à norma do programa na avaliação pós-intervenção [...] Os mesmos podem ter dado respostas mais condizentes com o que aprenderam com as atividades desenvolvidas no programa, e não propriamente com suas práticas". Tal fato reforça a ideia de que métodos mais apropriados para avaliar todo processo educacional devem ser desenvolvidos.

O estado nutricional avaliado pela antropometria também foi outro método empregado pelos estudos, já que se considera que o conhecimento em nutrição implique melhores escolhas alimentares e, consequentemente, tenham impacto no estado nutricional. Um estudo de revisão sistemática com metanálise realizado por Friedrich et al. 22 incluíram dois trabalhos que avaliavam o efeito da intervenção nutricional na redução do Índice de Massa Corporal (IMC) com 3.524 participantes. Tal estudo concluiu que as intervenções com a educação nutricional não mostraram efeito significativo na redução do IMC. O que pode ser explicado parcialmente pelo reconhecimento de que mudanças na massa corporal não ocorrem em curto período, sugerindo que esse pode não ser um método apropriado para avaliar intervenções educativas desenvolvidas em curto espaço de tempo.

Dessa maneira, é fundamental marcar que a eleição por métodos de estudos de semelhante natureza reflete substancialmente a permanência da perspectiva educativa pautada no behaviorismo, que foca hegemonicamente a adoção de novos comportamentos, conforme destacam alguns autores 19,23. Gazzinelli et al. 19, ao examinarem criticamente a educação em saúde durante as últimas décadas, destacam a distância entre o desenvolvimento das reorientações teóricas e metodológicas no campo, ressaltando a contribuição dos estudos da antropologia da saúde 
e das ciências sociais contemporâneas e a não tradução nas intervenções educativas concretas. Desse modo, segundo os autores, há um profundo hiato entre a teoria e a prática.

Esta perspectiva também foi encontrada nos estudos. Embora as metodologias das intervenções não estejam devidamente descritas, sabe-se que as bases teóricas são um obstáculo ao desenvolvimento de qualquer área do conhecimento e a educação nutricional não foge à regra ${ }^{1}$. Apenas três estudos analisados fundamentaram o processo educativo, sendo esses com as seguintes referências: a Teoria de Piaget; o referencial da estratégia de grupo operativo; e a educação problematizadora. A análise dos estudos selecionados neste trabalho entende a EAN como "um processo educativo no qual, através da união de conhecimentos e experiências do educador e do educando, vislumbra-se tornar os sujeitos autônomos e seguros para realizarem suas escolhas alimentares de forma que garantam uma alimentação saudável e prazerosa, propiciando, então, o atendimento de suas necessidades fisiológicas, psicológicas e sociais" 24 (p. 81).

O Marco de Referência de Educação Alimentar e Nutricional para Políticas Públicas ${ }^{9}$ (p. 23) ratifica o conceito acima e amplia-o, como “Educação Alimentar e Nutricional é um campo de conhecimento e de prática contínua e permanente, transdisciplinar, intersetorial e multiprofissional que visa promover a prática autônoma e voluntária de hábitos alimentares saudáveis. A prática da EAN deve fazer uso de abordagens e recursos educacionais problematizadores e ativos que favoreçam o diálogo junto a indivíduos e grupos populacionais, considerando todas as fases do curso da vida, etapas do sistema alimentar e as interações e significados que compõem o comportamento alimentar".

À luz dessa consideração, discute-se que a maioria dos estudos analisados apresentou como objetivo avaliar os resultados das intervenções desenvolvidas. Segundo Bordenave 25, as opções pedagógicas adotadas por um determinado contexto refletem também os objetivos desse referido contexto. E muitas vezes o interesse central está precisamente dirigido aos efeitos de sua aplicação. Ou seja, considera-se que, ao delinear as metodologias a serem implementadas com objetivo claro de avaliar, pode-se basear apenas no resultado a ser alcançado, deixando de lado a opção pedagógica adotada, que é essencial em um processo educativo. Ainda segundo este autor, todos os processos educativos, assim como suas respectivas metodologias e meios, têm por base uma concepção de como se consegue que as pessoas aprendam algo e, a partir daí, modifiquem seu comportamento.
Pode-se destacar que alguns estudos foram desenvolvidos conforme aquilo que determinados autores 25,26 classificam como a pedagogia da transmissão ou transferência de conhecimentos. Ela parte da premissa de que as ideias e conhecimentos são os pontos mais importantes da educação, assim são considerados os métodos como palestras e/ou apresentações, que em sua maioria se caracterizam como um exemplo do estilo vertical e tradicional dessa pedagogia. Um dos estudos refere que "o programa de educação nutricional foi desenvolvido com o objetivo de transmitir às crianças informações sobre alimentação e nutrição" 27 (p. 317).

Ao mesmo tempo, alguns estudos destacaram a preocupação com um processo que proporcionasse a participação dos alunos, ao passo que ressaltaram ao longo da metodologia informações como "buscou-se a participação e o envolvimento dos adolescentes [...] e durante as abordagens procurou-se ampliar a discussão da EN para além do enfoque biologicista" 28 (p. 12930) ou "adotou-se uma abordagem com base na homologia do processo" 29 (p. 313) ou ainda "o fechamento da oficina ocorria por meio de perguntas e respostas aos alunos avaliando-se a construção do conhecimento" 30 (p. 108).

De modo mais aprofundado, um estudo se destacou de forma geral, desde a proposição de seus objetivos a obter como resultado métodos e tecnologias de intervenção em EAN. A intervenção foi fundamentada na educação problematizadora proposta por Paulo Freire e foi ressaltado que, na sua concepção, procurou-se contextualizar o tema tratado no cotidiano de vida da comunidade, valorizando o trabalho local das famílias. Camossa et al. 31 sinalizam que a importância do processo de educação nutricional está em despertar no indivíduo o interesse pela alteração de seus hábitos alimentares, levando em consideração suas crenças, sua cultura e seus costumes. O resultado do estudo supracitado foi uma intervenção que envolveu não só os escolares, mas suas famílias, professores e a comunidade local e resultou também em algumas referências para aprimorar novas abordagens.

No que tange às principais estratégias abordadas, além da predominância dos métodos tradicionais (palestras, discussões e apresentações), notou-se também a associação com atividades lúdicas que foram frequentes. Atividades lúdicas são consideradas recursos metodológicos e se destacam como uma das maneiras mais eficazes de envolver os alunos nas atividades porque a brincadeira é algo inerente à criança, configurando em sua forma de trabalhar, refletir e discutir o mundo que a cerca 32 . 


\section{Conclusão}

Diante desses resultados, pode-se destacar que a relevância da EAN para a promoção do estilo de vida e alimentação saudáveis parece não estar sendo acompanhada pelos investimentos na pesquisa científica no campo, se for levada em conta a incipiência das publicações sobre a temática no período estudado. Soma-se ainda que os estudos apresentados optaram predominantemente por desenhos metodológicos baseados nos estudos epidemiológicos de intervenção que terminam por refletir a lacuna existente entre a teoria e a prática, indicando a necessidade de desenvolvimento de intervenções baseadas em metodologias inovadoras de educação em saúde, assim como métodos investigativos apropriados para tal perspectiva.

\section{Resumen}

La educación alimentaria y nutricional es vista como una estrategia para la promoción de hábitos alimentarios saludables, se cree que la escuela es un espacio apropiado para desarrollar esas acciones. El objetivo fue describir y analizar el panorama de la publicación científica sobre estudios de intervención en el campo de la educación alimentaria y nutricional en escuelas de Brasil. En ese estudio se realizó un repaso de la literatura, utilizando artículos publicados entre 2000 y 2011. Se observó que, a pesar de la importancia del tema, hay un bajo número de publicaciones en el área y la mayor parte fue publicada a partir de 2009. Los resultados demuestran una mejora en el conocimiento en nutrición y en las opciones alimentarias. No obstante, en la mayoría de los estudios que realizaron evaluaciones antropométricas no se observó cambios en el estado nutricional. Por ello, se optó por metodologías basadas en estudios epidemiológicos de intervención, apuntando la necesidad de intervenir en metodologías innovadoras de educación en salud y modelos de investigación que correspondan a los objetos de estudio.

Educación Alimentaria y Nutricional; Salud Escolar; Alimentación Escolar
O campo da EAN necessita de métodos aperfeiçoados e aprofundados que deem conta da subjetividade que perpassa o processo educativo e dos fatores que o cercam, como as histórias de vida, crenças e valores presentes na aprendizagem alimentar socioculturalmente construída. Para tanto, cabe considerar a contribuição do campo da socioantropologia da alimentação e nutrição em interface com outras ciências que fundamentam o ato educativo que podem trazer possibilidades teórico-metodológicas na construção de estudos mais consistentes no campo da saúde, alimentação e nutrição.

\section{Colaboradores}

F. P. Ramos e L. A. S. Santos participaram da concepção, análise e interpretação dos dados, redação do artigo e revisão crítica relevante do conteúdo intelectual e da aprovação da versão final. A. B. C. Reis participou da redação do artigo e revisão crítica relevante do conteúdo intelectual e da aprovação da versão final.

\section{Agradecimentos}

À Escola de Nutrição da Universidade Federal da Bahia pelo apoio. 


\section{Referências}

1. Boog MCF. Educação nutricional: passado, presente, futuro. Rev Nutr PUCCAMP 1997; 10:5-19.

2. Lima ES, Oliveira CS, Gomes MCR. Educação nutricional: da ignorância alimentar à representação social na pós-graduação do Rio de Janeiro, 19801998. Hist Ciênc Saúde-Manguinhos 2003; 10 604-35.

3. Departamento de Atenção Básica, Secretaria de Atenção à Saúde, Ministério da Saúde. Política nacional de alimentação e nutrição. Brasília: Ministério da Saúde; 2012.

4. Santos LAS. O fazer educação alimentar e nutricional: algumas contribuições para reflexão. Ciênc Saúde Coletiva 2012; 17:453-62.

5. Instituto da Cidadania. Projeto Fome Zero: uma proposta de política de segurança alimentar para o Brasil. São Paulo: Instituto da Cidadania; 2001.

6. Secretaria de Vigilância em Saúde/Secretaria de Atenção à Saúde, Ministério da Saúde. Política nacional de promoção da saúde. 3ạ Ed. Brasília: Ministério da Saúde; 2010.

7. Brasil. Decreto no 7.272 , de 25 de agosto de 2010 . Regulamenta a Lei o 11.346 , de 15 de setembro de 2006, que cria o Sistema Nacional de Segurança Alimentar e Nutricional - SISAN com vistas a assegurar o direito humano à alimentação adequada, institui a Política Nacional de Segurança Alimentar e Nutricional - PNSAN, estabelece os parâmetros para a elaboração do Plano Nacional de Segurança Alimentar e Nutricional, e dá outras providências. Diário Oficial da União 2010; 26 ago.

8. Ministério do Desenvolvimento Social. Encontro em Brasília discute Educação Alimentar e Nutricional. http:www.mds.gov.br (acessado em 21/ Abr/2012).

9. Secretaria Nacional de Segurança Alimentar e Nutricional, Ministério do Desenvolvimento Social e Combate à Fome. Marco de referência de educação alimentar e nutricional para as políticas públicas. Brasília: Ministério do Desenvolvimento Social e Combate à Fome; 2012.

10. Deminice R, Laus MF, Marins TM, Silveira SDO, Dutra-de-Oliveira JE. Impacto de um programa de educação alimentar sobre conhecimentos, práticas alimentares e estado nutricional de escolares. Alimentos e Nutrição 2007; 18:35-40.

11. Pacheco SSM. O hábito alimentar enquanto um comportamento culturalmente produzido. In: Freitas MCS, Fontes GAV, Oliveira N, organizadores. Escritas e narrativas sobre alimentação e cultura. Salvador: Edufba; 2008. p. 217-38.

12. Brasil. Lei no 11.947, de 16 de Junho de 2009. Dispõe sobre o atendimento da alimentação escolar e do Programa Dinheiro Direto na Escola aos alunos da educação básica; altera as Leis no 10.880, de 9 de junho de 2004, 11.273, de 6 de fevereiro de 2006 , 11.507, de 20 de julho de 2007; revoga dispositivos da Medida Provisória no 2.178-36, de 24 de agosto de 2001, e a Lei no 8.913, de 12 de julho de 1994; e dá outras providências. Diário Oficial da União 2009; 17 jun.
13. Brasil. Portaria interministerial no 1.010 , de 8 de maio de 2006. Institui as diretrizes para a Promoção da Alimentação Saudável nas Escolas de educação infantil, fundamental e nível médio das redes públicas e privadas, em âmbito nacional. Diário Oficial da União 2006; 9 mai.

14. Brasil. Decreto no 6.286, de 5 de dezembro de 2007. Institui o Programa Saúde na Escola - PSE, e dá outras providências. Diário Oficial da União 2007; $6 \mathrm{dez}$.

15. Santos LAS. Educação alimentar e nutricional no contexto da promoção de práticas alimentares saudáveis. Rev Nutr 2005; 18:681-92.

16. Brasil. Resolução/CD/FNDE no 38, de 16 de julho de 2009. Dispõe sobre o atendimento da alimentação escolar aos alunos da educação básica no Programa Nacional de Alimentação Escolar - PNAE. Diário Oficial da União 2009; 17 jul.

17. Pereira PR, Scagliusi FB, Batista SHS. Educação nutricional nas escolas: uma revisão. Nutrire Rev Soc Bras Aliment Nutr 2011; 36:109-29.

18. Pitanga FJG. Epidemiologia, atividade física e saúde. Rev Bras Ciênc Mov 2002; 10:49-54.

19. Gazinelli FG, Gazinelli A, Reis DC, Penna CMM. Educação em saúde: conhecimentos, representações sociais e experiências da doença. Cad Saúde Pública 2005; 21:200-6.

20. Bizzo MLG, Leder L. Educação nutricional nos parâmetros curriculares nacionais para o ensino fundamental. Rev Nutr 2005; 18:661-7.

21. Vargas ICS, Sichieri R, Sandre-Pereira G, Veiga GV. Avaliação de programa de prevenção de obesidade em adolescentes de escolas públicas. Rev Saúde Pública 2011; 45:59-68.

22. Friedrich RR, Schuch I, Wagner MB. Efeito de intervenções sobre o índice de massa corporal em escolares. Rev Saúde Pública 2012; 46:551-60.

23. Vasconcelos EM. Educação popular: de uma prática alternativa a uma estratégia de gestão participativa das políticas de saúde. Physis (Rio J.) 2004; 14:67-83.

24. Lima KA. Análise do processo de construção do conhecimento dietoterápico de pacientes diabéticos atendidos no programa saúde da família do município de Araras [Dissertação de Mestrado]. Araraquara: Universidade Estadual Paulista; 2004.

25. Bordenave JED. La transferencia de tecnología apropiada al pequeño agricultor. Revista Interamericana de Educação de Adultos 1980; 3:75-102.

26. Freire P. Pedagogia do oprimido. Rio de Janeiro: Editora Paz \& Terra; 1987.

27. Fernandes PS, Bernardo CO, Campos RMMB, Vasconcelos FAG. Avaliação do efeito da educação nutricional na prevalência de sobrepeso/obesidade e no consumo alimentar de escolares do ensino fundamental. J Pediatr (Rio J.) 2009; 85:315-21.

28. Zancul MS, Valeta LN. Educação nutricional no ensino fundamental: resultados de um estudo de intervenção. Nutrire Rev Soc Bras Aliment Nutr 2009; 34:125-40. 
29. Gaglianone CP, Taddei JAAC, Colugnati FAB, Magalhães CG, Davanço GM, Macedo L, et al. Educação nutricional no ensino público fundamental em São Paulo, Brasil: projeto Redução dos Riscos de Adoecer e Morrer na Maturidade. Rev Nutr 2006; 19:309-20.

30. Botelho LP, Zanirati VF, Paula DV, Lopes ACS, Santos LC. Promoção da alimentação saudável para escolares: aprendizados e percepções de um grupo operativo. Nutrire Rev Soc Bras Aliment Nutr 2010; 35:103-16.

31. Camossa ACA, Costa FNA, Oliveira PFO, Figueiredo TP. Educação nutricional: uma área em desenvolvimento. Alimentação e Nutrição 2005; 16 : 349-54.

32. Dallabona SR, Mendes SMS. O lúdico na educação infantil. Revista de Divulgação Técnico-Científica do ICPG 2004; 1:107-12.

33. Costa AGM, Gonçalves AR, Suart DA, Suda G, Piernas P, Lourena LR, et al. Avaliação da influência da educação nutricional no hábito alimentar de crianças. Rev Inst Ciênc Saúde 2009; 27:237-43.

34. Gabriel CG, Santos MV, Vasconcelos FAG. Avaliação de um programa para promoção de hábitos alimentares saudáveis em escolares de Florianópolis, Santa Catarina, Brasil. Rev Bras Saúde Matern Infant 2008; 8:299-308.
35. Carvalho AP, Oliveira VB, Santos LC. Hábitos alimentares e práticas de educação nutricional: atenção a crianças de uma escola municipal de Belo Horizonte, Minas Gerais. Pediatria (São Paulo) 2010; 32:20-7.

36. Anzolin C, Ouriques CM, Hofelmann DA, Mezadri T. Intervenções nutricionais em escolares. Rev Bras Promoç Saúde 2010; 23:297-306.

37. Garcia RN, Almeida EB, Souza K, Vechi G. Nutrição e odontologia: a prática interdisciplinar em um projeto de extensão. RSBO 2008; 5:50-7.

38. Boog MCF. Programa de educação nutricional em escola de ensino fundamental de zona rural. Rev Nutr 2010; 23:1005-17.

39. Yokota RTC, Vasconcelos TF, Pinheiro ARO, Schmitz BAS, Coitinho DC, Rodrigues MLCF. Projeto "a escola promovendo hábitos alimentares saudáveis": comparação de duas estratégias de educação nutricional no Distrito Federal, Brasil. Rev Nutr 2010; 23:37-47.

Recebido em 26/Nov/2012

Versão final reapresentada em 22/Jul/2013

Aprovado em 01/Ago/2013 